\title{
The Outcome of Primary Anastomosis and the Long Term Follow Up of Preterm Infants Undergoing Surgery for Necrotizing Enterocolitis
}

\author{
Adi Rov ${ }^{1,4}$, David Savitzki ${ }^{2,4}$, Alon Yulevich ${ }^{1,4}$, Ben Elisha $\mathbf{M}^{3,4}$, Acawi I ${ }^{3,4}$ and Yechiel Sweed ${ }^{1,4^{*}}$ \\ ${ }^{1}$ Pediatric Surgery, Galilee Medical Center, Israel, \\ ${ }^{2}$ Pediatric Neurology and Child Developmental Unit, Galilee Medical Center, Israel, \\ ${ }^{3}$ Neonatal Intensive Care Unit, Galilee Medical Center, Israel, \\ ${ }^{4}$ Azrieli Faculty of Medicine- Bar-Ilan University, Israel
}

Submission: March 13, 2020 Published: April 06, 2020

*Corresponding author: Yechiel Sweed, Pediatric Surgery, Galilee Medical Center, Nahariya, Israel, E-mail: drsweed@gmail.com

\begin{abstract}
Objective: To investigate the safety and effectiveness of primary anastomosis (PA) in infants with complicated necrotizing enterocolitis (NEC) and the short and long-term outcomes, including the neurodevelopmental outcomes.

Methods: A retrospective analysis of medical records of all infants diagnosed with NEC in the years 2000-2016. Long-term outcome data were taken from medical records and parental questionnaires.

Results: Of 98 infants diagnosed with NEC, 40 were surgically treated (22 PA, 9 stoma, 9 peritoneal drainage (PD)). PA had shorter length of parenteral nutrition ( 20 vs. 34 days, $p=0.215$ ), antibiotic treatment (10 vs. 14 days, $p=0.053$ ) and hospitalization ( 48 vs. 106 days, $p=0.026)$ compared to stoma. Stoma group infants who needed more than one surgical intervention due to complications was three times higher (66\% vs $22 \%, p=0.038$ ) and $57 \%$ of stoma infants developed short bowel syndrome compared to $33 \%$ of PA infants. There was no statistically significant difference between PA and stoma in mortality rate $(27 \%$ vs $22 \%, \mathrm{p}=1.00)$. Normal development at 1 -2 years after discharge was found in $40 \%$ of PA and $14 \%$ of stoma. Severe neurodevelopmental impairment (NDI) was more common in stoma (70\%) than in PA (20\%). $70 \%$ of PA infants were integrated into a regular education framework compared to $28 \%$ of stoma.

Conclusion: PA is a safe and effective surgical technique in the management of complicated NEC, with the same mortality rate as stoma, but, with lower morbidity in the short term and better long-term neurodevelopmental outcomes.

Keywords: Necrotizing Enterocolitis; Primary anastomosis; Stoma; Peritoneal Drainage; Neurodevelopmental outcome

Abbreviations: CP: Cerebral Palsy; HC: Head Circumference; NDI: Neurodevelopmental Impairment; ADHD: Attention Deficit Hyperactivity Disorder; VLBW: Very Low Birth Weight; ELBW: Extremely Low Birth Weight; TPN: Total Parenteral Nutrition; IVH: Intraventricular Hemorrhage;
\end{abstract} CS: Caesarean Section

\section{Introduction}

Necrotizing enterocolitis (NEC) is the most common medical and surgical gastrointestinal emergency in preterm infants; $1-5 \%$ of the infants hospitalized in neonatal critical care units develop NEC [1]. The incidence of NEC is inversely proportional to birth weight and gestational age: higher incidence correlates to earlier gestational age and lower birth weight. In recent years there has been an increase in the incidence of NEC due to the increase in premature births by Caesarean section for therapeutic reasons compounded with the advancement in neonatal care technology that has increased survival of previously fatal conditions [2]. Mortality rates, however, remain as high as $15-30 \%$ [3]. Many cases of NEC are managed medically, but roughly $20 \%$ to $40 \%$ of patients require surgical intervention [3]. There is no actual consensus on the most appropriate surgical technique for the management of NEC. In cases of very-low-weight infants or great hemodynamic instability, PD has been utilized as the firststep therapy [1]. PD is performed as a bedside procedure, does not require general anesthesia and avoids bowel resection complications; however, over $70 \%$ of these infants may require a laparotomy for which mortality rates are significantly higher $[4,5]$. For many years, resection of the non- viable intestine and stoma was considered the gold standard for the surgical treatment of NEC. It was assumed that primary intestinal anastomosis will not 
heal in the presence of sepsis or peritoneal contamination. Also, of concern was the inability of surgeons to accurately determine the full extent of disease during surgery and the fear of resection of more intestine than required, anastomotic leak and strictures. Stoma complications have been seen in up to $68 \%$ of patients [1] and the need for a second intervention for closure of the stoma led some surgeons to prefer the PA approach. In recent years studies have described PA as a safe technique with low morbidity and mortality in the short-term outcomes compared to stoma $[1,6,7]$. In the long-term follow-up, however, a very limited number of studies have evaluated children surviving NEC after surgery beyond the 6-month time point. Even less is known about the effects of the different surgical approaches later on in their childhood. Neurodevelopmental impairment (NDI) is one of the most prevalent long-term complications, affecting as many as $50 \%$ of the infants surviving NEC. NDI is 2.5 times more likely to develop in the surgically- treated infants [8]. A study that investigated long-term neurodevelopmental outcomes of primary- school-age children who survived NEC surgery found favorable cognitive and motor development following PA compared to stoma, when there was no difference in prematurity and the severity of disease [9]. In the last 15 years, PA has been the preferred technique in our practice. We decided to analyze and report our data concerning the safety and effectiveness of PA in patients with complicated NEC and the short and long-term outcomes, including the neurodevelopmental outcomes.

\section{Methods}

\section{Patients and setting}

We conducted a descriptive retrospective analysis of the medical records of all infants diagnosed with NEC in Galilee Medical Center from January 2000 through January 2016. Exclusion criteria included pan-intestinal disease, death in less than 24 hours and missing patient charts. Long-term outcome data were taken from medical records in the Neurodevelopmental Unit and parental questionnaires that examined the clinical, functional and developmental status of the child today. Approval of the Institutional- Ethics- Committee was obtained prior to the study's start, and patient confidentiality was maintained throughout the study.

\section{Study variables}

The data collected included gestational age, birth weight, gender, type of delivery (vaginal or cesarean section), Apgar score, intraventricular hemorrhage, age at onset of disease, preoperative Bell's grade of NEC (clinical, laboratory and radiology findings), indication for surgery, surgical intervention performed (PD, stoma, PA, peritoneal drainage followed by laparotomy), place of surgery (NICU or OR) and intraoperative assessment and findings (location of the disease, number of areas of intestine affected, conservation of the ileocecal valve, number of anastomoses). Short term outcomes included postoperative parameters: time to bowel movements, antibiotic treatment, time to full enteral feeding, length of hospitalization, complications (wound infection, stoma complications, anastomosis complications, further surgical intervention, short bowel syndrome) and mortality. The longterm outcomes included neurodevelopmental and functional assessment with parameters of cognitive and motor skills, auditory or visual impairments, social adaptation and function, developmental therapy, education framework, learning disabilities and ADHD.

\section{Statistical analysis}

Quantitative data were summarized using mean, standard deviation, median and range. Qualitative data were summarized using frequencies and percentages and displayed by graphs and diagrams. The variables were compared using Chi square test and Fisher's exact test for qualitative data and Wilcoxon rank sum test for quantitative data. P values lower than 0.05 were considered statistically significant.

\section{Results}

110 infants were diagnosed with NEC during the study period, corresponding to $1 \%$ of all the preterm infants in the NICU during those years. Of these, 98 infants were included in the study; 42 were treated surgically and 56 non-surgically (Figure 1). In the surgical group, PA was performed on 22 infants (55\%) of whom three were treated first with PD and one with "clip and drop" due to clinical state. Nine infants (22.5\%) underwent stoma following bowel resection, three of them were treated first with PD. The remaining nine infants $(22.5 \%)$ were treated by drainage alone. Two infants had pan- intestinal disease and were excluded from the study (Figure 2).

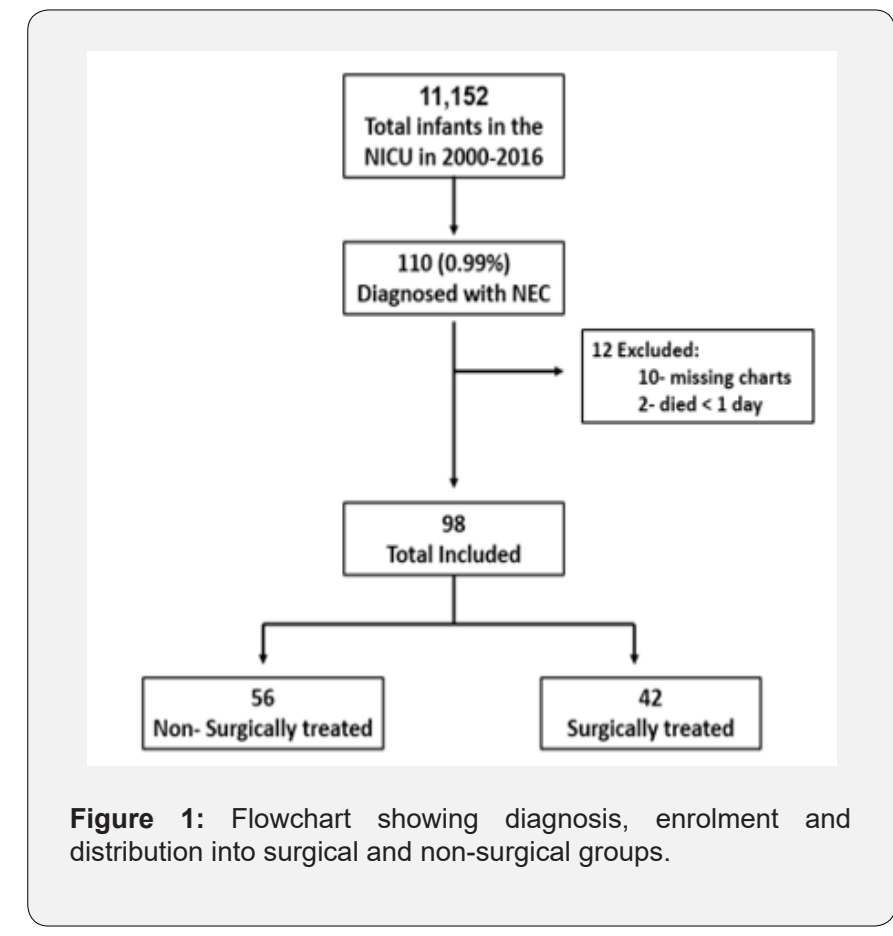




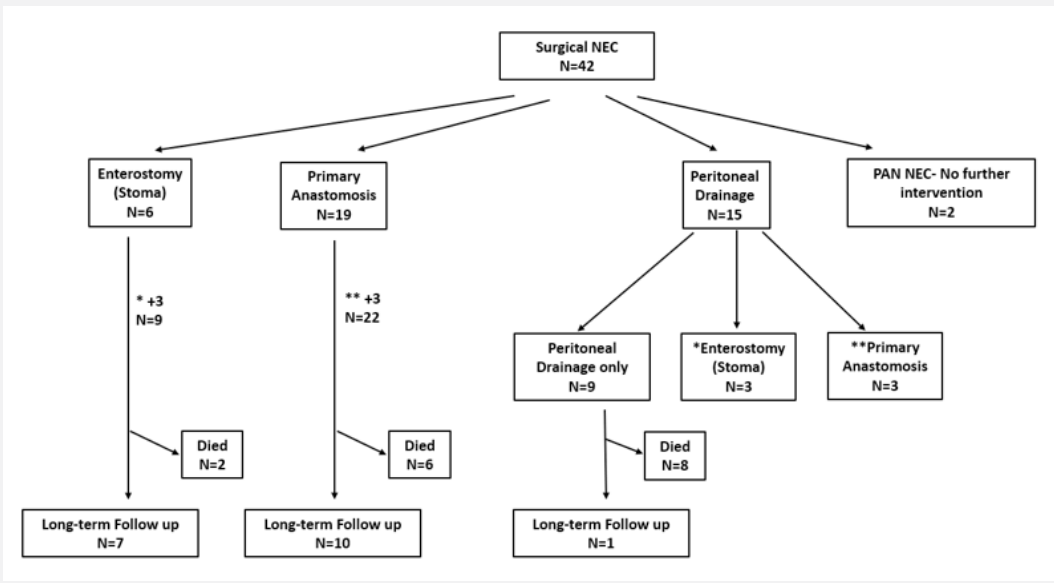

Figure 2: Flowchart showing the surgical intervention performed, mortality and follow-up.

\section{Population}

The median gestational age was 28 weeks (range 23-40) in both PA and stoma infants. Median birth weight was $1021.5 \mathrm{gr}$ (range 668-3375) in PA infants and 1223 gr (range 826-2635) in the infants who underwent stoma. In the weight distribution, 50\% of the infants with PA weighed < 1000 gr compared to $33 \%$ in the stoma group. Median Apgar score after 5 minutes was 8 in both groups, but the range in the PA group was greater. The median age for the onset of disease was 7 days (range 1-42) and 9 days (range 4-20) in the PA and stoma infants, respectively. Intraventricular hemorrhage (IVH) was seen in $7 \%$ of the PA group and $4 \%$ of the stoma group; in both groups, grade II was the most prevalent. There was no significant statistical difference in any of the infants' characteristics between the two groups of surgical techniques. More detailed patient characteristics are presented in Table 1.

Table 1: Infants characteristics.

\begin{tabular}{|c|c|c|c|}
\hline & $\begin{array}{l}\text { Primary Anastomosis } \\
\qquad \mathrm{N}=22\end{array}$ & Stoma $\mathbf{N}=9$ & $\mathbf{P}$ \\
\hline \multicolumn{4}{|l|}{ Sex n $(\%)$} \\
\hline M & $12(54.5)$ & $4(44.4)$ & $0.704^{*}$ \\
\hline $\mathrm{F}$ & $10(45.5)$ & $5(55.6)$ & \\
\hline Gestational age (wk) Median (min- max) & $28.5(23-40)$ & $28(24-36)$ & $0.723^{* *}$ \\
\hline \multicolumn{4}{|l|}{ Weight (g) n (\%) } \\
\hline$>2500$ & $5(22.7)$ & $1(11.1)$ & \\
\hline LBW & $5(22.7)$ & $2(22.2)$ & \\
\hline VLBW & $1(4.5)$ & $3(33.3)$ & - \\
\hline ELBW & $11(50)$ & $3(33.3)$ & \\
\hline \multicolumn{4}{|l|}{ Apgar score Median (min- max) } \\
\hline $1 \mathrm{~min}$ & $6(0-9)$ & $7(5-9)$ & $0.146^{* *}$ \\
\hline $5 \mathrm{~min}$ & $8(1-10)$ & $8(8-10)$ & $0.465^{* *}$ \\
\hline \multicolumn{4}{|l|}{ Type of delivery n (\%) } \\
\hline Vaginal & $8(36.4)$ & $3(33.3)$ & $1.00^{*}$ \\
\hline CS & $14(63.6)$ & $6(66.7)$ & \\
\hline \multicolumn{4}{|l|}{ Multiple pregnancy n (\%) } \\
\hline Single & $15(68.2)$ & $6(66.7)$ & $1.00^{*}$ \\
\hline Twins & $6(27.3)$ & $3(33.3)$ & \\
\hline Triplets & $1(4.5)$ & $0(0)$ & \\
\hline
\end{tabular}




\section{Academic Journal of Pediatrics \& Neonatology}

\begin{tabular}{|c|c|c|c|}
\hline Family relationship between the parents n (\%) & 5 (22.7) & $0(0)$ & $0.286^{*}$ \\
\hline \multicolumn{4}{|l|}{ Type of feed n (\%) } \\
\hline Enteral +/- TPN & $13(59.1)$ & $6(66.7)$ & $1.00^{*}$ \\
\hline TPN only & $9(40.9)$ & $3(33.3)$ & \\
\hline IVH n $(\%)$ & $7(31.8)$ & $4(44.4)$ & $0.683^{*}$ \\
\hline Age at onset of disease (d) Median (min- max) & $7(1-42)$ & $9(4-20)$ & $0.421^{* *}$ \\
\hline \multicolumn{4}{|l|}{ Modified Bells classification n (\%) } \\
\hline $1 \mathrm{~A}$ & $1(4.5)$ & $0(0)$ & \\
\hline 1B & $0(0)$ & $0(0)$ & \\
\hline $2 \mathrm{~A}$ & $1(4.5)$ & $1(11.1)$ & - \\
\hline $2 \mathrm{~B}$ & $7(31.8)$ & $2(22.2)$ & \\
\hline $3 \mathrm{~A}$ & $3(13.6)$ & $0(0)$ & \\
\hline $3 \mathrm{~B}$ & $10(45.5)$ & $6(66.7)$ & \\
\hline
\end{tabular}

M: Male; F: Female; LBW: Low Birth Weight (<2500 gr); VLBW: Very Low Birth Weight (<1500 gr); ELBW: Extremely Low Birth Weight (<1000 gr); TPN: Total Parenteral Nutrition; IVH: Intraventricular Hemorrhage; CS: Caesarean Section

*Fisher's Exact Test; ** Wilcoxon Rank-Sum Test

\section{Indication for surgery}

Pneumoperitoneum was seen in $67 \%$ of the stoma group and $46 \%$ of the PA group, with no statistical difference. $33 \%$ of both groups had portal air gas. There were no statistical differences in worsening clinical condition nor in laboratory findings between the groups.

\section{Intraoperative assessment and findings}

Over half of the operated infants (55\%) underwent the surgery in the NICU and not in the OR. Intestinal necrosis and perforation were the most prevalent surgical findings, seen in $68 \%$ of PA and $67 \%$ of stoma infants. The location of the disease for infants who underwent PA was diverse and included the colon (33\%) and ileum $(22 \%)$ as unifocal or bifocal $(16.7 \%)$ and the jejunum with ileum $(16.7 \%)$. The areas of intestine affected in the stoma infants were jejunum and ileum together in $56 \%$ of the infants; as many as $86 \%$ had bifocal disease compared to $57 \%$ of the PA infants, no statistical difference. Ileocecal valve resection was performed in $27 \%$ of the PA infants and $37 \%$ of the stoma infants with no statistical difference. Most of the infants who underwent PA had one anastomosis (90\%) and two had 2 anastomoses (Table 2).

Table 2: Intraoperative assessment and findings.

\begin{tabular}{|c|c|c|c|}
\hline & $\begin{array}{l}\text { Primary Anastomosis } \\
\qquad \mathrm{N}=22\end{array}$ & Stoma $\mathbf{N}=9$ & $\mathbf{P}^{*}$ \\
\hline Surgery in the NICU n (\%) & $12(54.5)$ & $5(55.6)$ & - \\
\hline \multicolumn{4}{|l|}{ Location of the disease $\mathrm{n}(\%)$} \\
\hline Ileum & $4(22.2)$ & $0(0)$ & \\
\hline Jejunum & $1(5.6)$ & $0(0)$ & \\
\hline Ileum+ jejunum & $3(16.7)$ & $5(55.6)$ & \\
\hline Colon & $6(33.3)$ & $1(11.1)$ & - \\
\hline Ileum+ colon & $3(16.7)$ & $1(11.1)$ & \\
\hline Colon+ rectum & $0(0)$ & $1(11.1)$ & \\
\hline Most of intestine & $1(5.6)$ & $1(11.1)$ & \\
\hline \multicolumn{4}{|c|}{ Number of areas of intestine affected $n(\%)$} \\
\hline Unifocal & $6(42.9)$ & $1(14.3)$ & 0.337 \\
\hline Bifocal & $8(57.1)$ & $6(85.7)$ & \\
\hline \multicolumn{4}{|l|}{ Surgical findings n (\%) } \\
\hline Necrosis & $4(18.2)$ & $2(22.2)$ & \\
\hline Necrosis+ perforation & $15(68.2)$ & $6(66.7)$ & - \\
\hline Necrosis+ stricture & $1(4.5)$ & $1(11.1)$ & \\
\hline
\end{tabular}




\section{Academic Journal of Pediatrics \& Neonatology}

\begin{tabular}{|c|c|c|c|}
\hline Perforation & $12(9.1)$ & $0(0)$ & $3(37.5)$ \\
\hline Ileocecal valve resection n (\%) & $6(27.3)$ & & 0.666 \\
\hline Number of anastomoses n (\%) & & - & - \\
\hline One anastomosis & $20(90.9)$ & & \\
\hline Two anastomoses & $2(9.1)$ & \\
\hline
\end{tabular}

*Fisher's Exact Test

\section{Short term outcomes}

The median length of parenteral nutrition was 20 days (range 10-69) in the PA group compared to 34 days (range 14-90) in the stoma group, $\mathrm{p}=0.215$. The duration of antibiotic treatment was a median of 10 days (range 5-20) in the PA group versus 14 days (range 9-30) in the stoma group, $p=0.053$. The prominent difference was in hospitalization time, a median 48 days (range 15-166) in infants who underwent PA vs. a median 106 days (range 35-180) in infants who underwent stoma, $\mathrm{p}=0.026$ (Figure 3). One-third of the infants in the stoma group had stoma complications: one infant had severe electrolyte disorder leading to renal failure, a second infant had an infection of the skin around the stoma due to a high-output stoma also causing acute renal failure and a third infant had an infection around the stoma but had no further complications. None of the PA infants had anastomosis complications. The number of infants who needed more than one surgical intervention due to complications (not including stoma closure surgery) was three times higher in stoma infants (66.7\% vs $22.7 \%, \mathrm{p}=0.038$ ) and the need for more than two surgical interventions occurred only in the stoma group. $57 \%$ of the infants who underwent stoma developed short bowel syndrome (SBS) compared to $33 \%$ of the PA group, $\mathrm{p}=0.376$ (Table 3 ).

Table 3: Post- operative short time outcomes.

\begin{tabular}{|c|c|c|c|}
\hline & $\begin{array}{l}\text { Primary Anastomosis } \\
\qquad \mathrm{N}=22\end{array}$ & Stoma $\mathbf{N}=9$ & $\mathbf{P}^{*}$ \\
\hline Wound infection n (\%) & $5(23.8)$ & $1(12.5)$ & 0.647 \\
\hline Anastomosis leak n (\%) & $0(0)$ & - & - \\
\hline Infection around the stoma $\mathrm{n}(\%)$ & - & $2(22.2)$ & - \\
\hline Sever electrolyte disorder $\mathrm{n}(\%)$ & - & $1(11.1)$ & - \\
\hline Renal failure n (\%) & - & $2(22.2)$ & - \\
\hline More than one surgical intervention due to complications n (\%) & $5(22.7)$ & $6(66.7)$ & 0.038 \\
\hline More than 2 surgical intervention due to complications n (\%) & $0(0)$ & $3(33.3)$ & 0.258 \\
\hline Short Bowel Syndrome n (\%) & $5(33.3)$ & $4(57.1)$ & 0.376 \\
\hline Mortality n (\%) & $6(27.3)$ & $2(22.2)$ & 1 \\
\hline
\end{tabular}

*Fisher's Exact Test

Figure 3: Post- operative short time outcome. 


\section{Mortality}

Survival rate was $74 \%$ (23/31), with no statistical difference between the PA and stoma groups in mortality rate $(27 \%$ vs $22 \%$, $\mathrm{p}=1.00$ ) (Table 3).

\section{Long-term outcomes: neurodevelopmental functional assessment}

Out of the 23 infants who survived, we located 17, of whom 10 had undergone PA and seven had undergone stoma. Of the 17 , eight were $<6$ years of age and 9 were $>6$ years of age. One child from the PA group was suffering from cerebral palsy (CP) and one child from the stoma group was diagnosed with Down syndrome. The groups were too small for statistical tests. Over $90 \%$ of the infants needed developmental treatment. The most prominent treatments were physiotherapy (88\%) and occupational therapy (81\%). There were no differences between the two groups in weight and head circumference at one year of age, but the prevalence of normal development was higher in the
PA children with $40 \%$ of that group showing normal development at 1-2 years after discharge compared to $14 \%$ of the stoma group. Also, $70 \%$ of the infants who underwent PA were integrated into a regular educational framework compared to $28 \%$ of those who underwent stoma (Figure 4). In order to check the severity of the neurodevelopmental impairment (NDI) four parameters were examined: gross motor, fine motor, language and social adaptation and function. The NDI was divided into severe, mild and normal range. In the stoma group the NDI was severe in all 4 parameters as opposed to mild NDI in the PA group: severe gross motor, fine motor and language impairment was recorded in $71 \%$ of the stoma group compared to $20 \%, 11 \%$ and $30 \%$, respectively, in the PA group. Of the children who had undergone stoma, $57 \%$ had severe social adaptation and function impairment compared to $11 \%$ of the PA children (Figure 5). Functional impairment was examined in children $>6$ years old. There was no difference between the stoma and PA groups, but we did find that the incidence of learning disabilities and ADHD was $30 \%$ and $36 \%$, respectively, in these groups (Figure 6).

CP: Cerebral Palsy; HC: Head Circumference

Figure 4: Neurodevelopmental assessment: 0-6 years old.
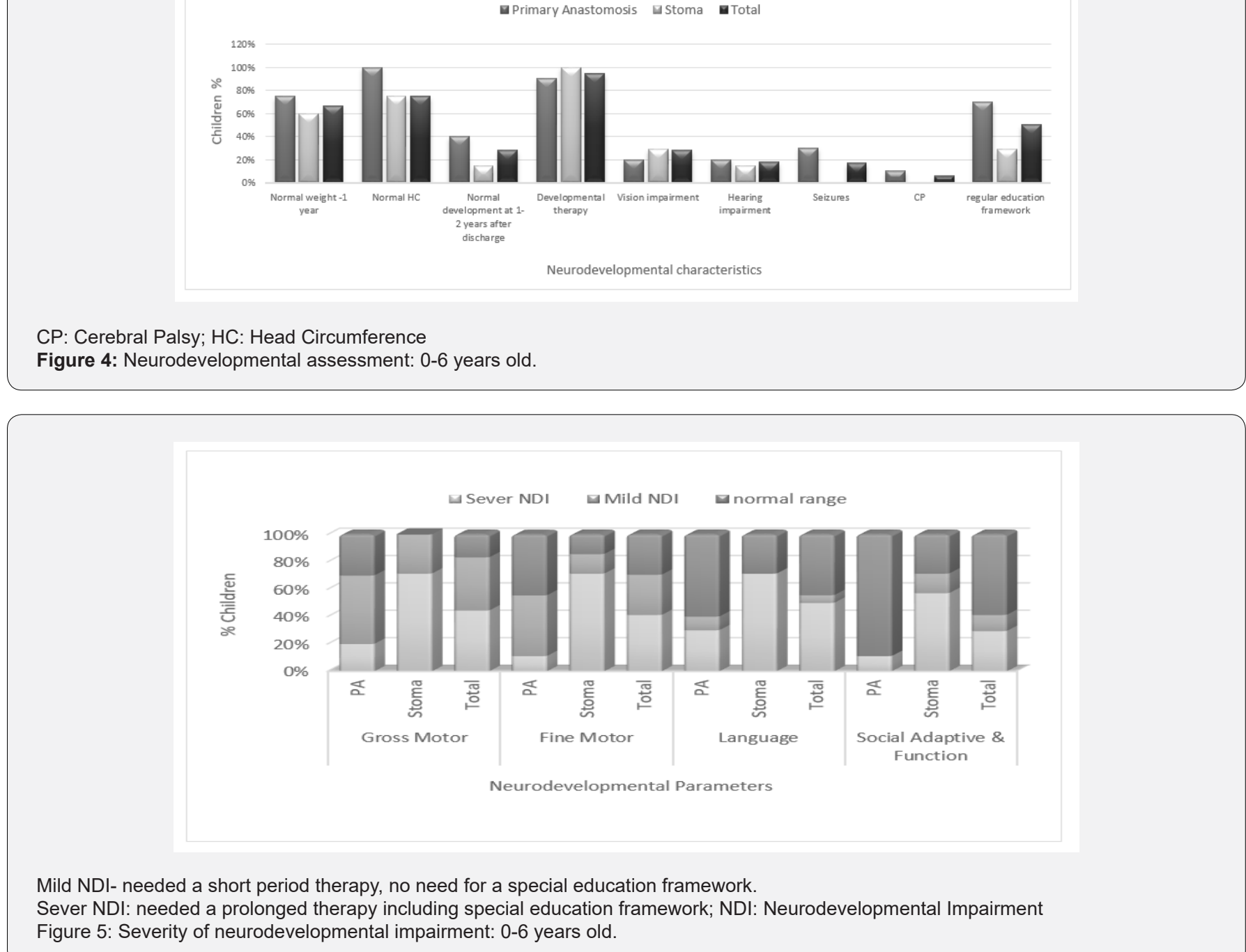


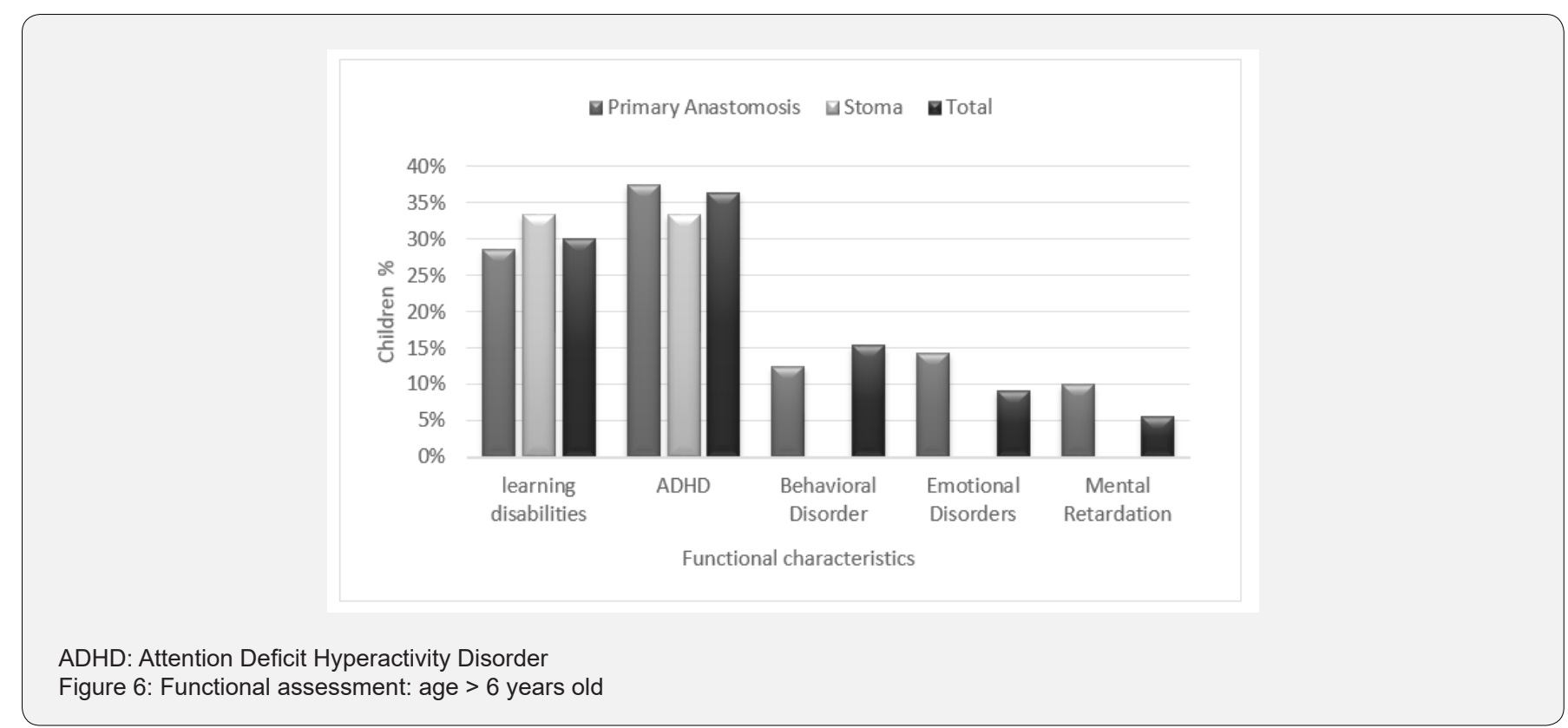

\section{Discussion}

This retrospective study included data from all the infants who were treated surgically for complicated NEC in over 15 years of practice in one medical center. We found primary anastomosis to be a safe and effective surgical technique in both short postoperative and long neurodevelopmental outcomes compared to the gold standard technique of stoma, with no statistical differences in age, weight, severity or extent of disease. Although the patients' characteristics and surgical findings showed no difference, a selection bias whereby surgeons were more prone for stoma in more critically ill infants cannot be ruled out. Stoma formation has traditionally been considered the safest approach to managing complicated NEC in infants given the unfavorable conditions of peritonitis, inflammation, sepsis and potentially compromised bowel. Also of concern is the fear of PA complication such as leaks and strictures $[1,10,5,6]$. In the current study we found wound infection to be two times higher in the PA group, but we found no further anastomosis complications such as leaks or strictures in any of the infants. On the other hand, in infants who underwent stoma there were stoma complications in one-third of the infants including infection, electrolyte disorder and renal failure. Moreover, the number of infants who needed more than one surgical intervention due to complications was three times higher in the stoma group compared to the PA group ( $\mathrm{p}=0.038$ ) and onethird of that group needed more than one surgical intervention. In the post-operative management, the length of TPN (Total Parenteral Nutrition) use and the time to full enteral feeding was shorter in the PA group. Duration of antibiotic treatment was also shorter in the PA infants, (not statistically significant), although the strong relation between the two groups $(p=0.053)$ may be explained by the small size of the study. Hospitalization time was significantly shorter in the PA infants as opposed to the stoma infants $(\mathrm{p}=0.026)$. This finding supported the findings by Griffiths et al $(n=50)$ where the length of hospital stay, the period of total parenteral nutrition and the time to full feeds were all shorter in the PA group, with no increase in short- or long-term morbidity or mortality [11]. An argument that appears at times in the professional literature against the PA procedure is the resection of unnecessary long segments of bowel thereby predisposing to short gut $[1,6]$. This was not the case in our study where short bowel syndrome was, in fact, more prevalent in the stoma group probably due to additional surgical intervention as a result of complications and also the fact that every procedure of stoma closure requires an additional bowel resection to create anastomosis. Griffiths et al's study [11] reported that the length of bowel resection in both stoma and PA groups was similar. Hofman et al [12] also came to a similar conclusion with no short gut cases in the PA group. Mortality rate was similar in both stoma and PA groups. Our finding correlates with those reported in the medical literature in both the mortality rate which stands at $15 \%-30 \%$ and the lack of difference between the two groups $[3,6,9,10]$. It is probable that survival was more dependent on the severity of the disease and the associated medical problems of prematurity than on the type of operation. In the long-term follow-up we found that over $90 \%$ of the infants needed developmental supportive treatment. The most prominent treatments were physiotherapy and occupational therapy. NDI is a common complication in infants treated surgically for NEC, but it is difficult to isolate the primary cause, since prematurity causes a wide range of comorbidities which might also play a role in developing NDI. The length of hospitalization of infants has been strongly associated with developmental progress at 1 to 2 years of age [13]. The NICU exposes the child to stressors, such as bright lights and excessive noise, which could also influence the outcome [14]. In the current study, we found that infants treated by PA had a significantly shorter hospitalization time compared 
to those who underwent stoma $(\mathrm{p}=0.026)$ and, indeed, in that group the percentage of children who had normal development at 1-2 years after discharge and who were integrated into a regular educational framework was significantly higher. There was mild NDI in the PA group and severe impairment in the stoma group. This strengthens the findings of Ta et al who also showed an association between the presence of a stoma and significantly worse motor and cognitive neurodevelopmental outcomes, when there was no difference in prematurity and the severity of disease [9]. This may be explained by higher losses of fluids, electrolytes and nutrition via the stoma that may result in malnutrition leading to inadequate neurodevelopment $[1,9]$.

The incidence of learning disabilities and ADHD in both groups was three times higher than the known incidence in healthy children. Based on the published literature, the prevalence of learning disabilities and ADHD among children and adolescence is $10 \%[15,16,17]$. In this study we found these disorders in $30 \%$ of the surgical NEC population. In a meta-analysis included 64,061 children born preterm, ADHD and learning disabilities was diagnosed twice as often in preterm children [18]. In other words, the group of children with NEC who were treated surgically experienced an influencing factor on learning disabilities and ADHD beyond the influence of prematurity itself. It is important to emphasize that, in the examination of long- term outcomes, the small study size did not allow statistical analysis and conclusions. We did see a tendency toward development of NDI in children treated surgically for NEC with differences between the techniques of PA and stoma. These findings underlie the necessity for further, larger studies to evaluate the effect of surgical intervention and the difference between surgical techniques on NDI. The limitations of our study are the retrospective methodology, the lack of randomicity in choosing the surgical techniques and the difficulty in collecting accurate and full data from a period of 16 years. It is difficult to exclude the selection bias regarding the operative approach that may have been impacted by the severity of the infant's condition, the infant's weight and the "surgeon's preference" that has been pointed out in many studies [7].

Due to the fact that the majority of the infants in the study were preterm, it is difficult to separate the effect of morbidity and other medical problems on the course of treatment and the results of the study. The sample size is relatively small, although the number of subjects in this study is similar to and even larger than the samples appearing in the medical literature. In the longterm follow-up, it was difficult to perform statistical tests and reach conclusions due to the small sample. We did find a trend in our results and these findings underline the necessity of further study of larger groups to evaluate the effect of treatment modality on long- term neurodevelopmental outcome. Because the surgical technique depends on the preference of the surgeon and the prospective comparative difficulty in the use of the various surgical techniques, it is difficult to reach clear conclusions about one technique preference over another. Further research is required in large groups of infants diagnosed with NEC to examine and evaluate the long-term effects of the disease and its various treatments.

\section{Conclusion}

Despite the widely held belief among most pediatric surgeons in the world that stoma is the safest and most preferred technique for treating complicated NEC, the results of this study showed that primary anastomosis is a safer and more effective method with better short-term outcomes and lower morbidity but with no difference in mortality rates. In the long-term neurodevelopmental follow-up we also found that the use of PA resulted in better outcomes than the conventional stoma technique. This study reinforced the recent reports in the medical literature that have shown a preference for the PA technique and also strengthened the need to continue monitoring the development of these infants over time.

\section{References}

1. Miguel Guelfand, Marcela Santos, Maricarmen Olivos, Alejandra Ovalle (2012) Primary anastomosis in necrotizing enterocolitis: the first option to consider. Pediatr Surg Int 28(7): 673-676.

2. Thomas Peter Fox, Charles Godavitarne (2012) What Really Causes Necrotizing Enterocolitis?. ISRN Gasroenterology 2012: 628317.

3. Marion CW Henry, R Lawrence Moss (2008) Neonatal necrotizing enterocolitis. Seminars in Pediatric Surgery 17: 98-109.

4. Clare M Ress, Simon Eaton, Edward M Kiely, Angie M Wade, Kieran McHugh, et al. (2008) Peritoneal Drainage or Laparotomy fo Neonatal Bowel Perforation? Annals of Surgery 248(1): 44-51.

5. Cynthia D Downard, Elizabeth Renaud, Shawn D St, Abdullah F, Islam S, et al. (2012) Treatment of necrotizing enterocolitis: an American Pediatric Surgical Association Outcomes and Clinical Trials Committee systematic review. Journal of Pediatric Surgery 47(11): 2111- 2122.

6. Michael Singh, Anthony Owen, Sobbia Gull, Antonino Morabito, Adrian Bianch (2006) Surgery for intestinal perforation in preterm neonates: anastomosis vs stoma. Journal of Pediatric Surgery 41(4): 725- 729

7. Ramanathapura N Haricharan, Jade Palazzola Gallimore, Ahmed Naser (2017) Primary anastomosis or ostomy in necrotizing enterocolitis? Pediatric Surgery International 33(11): 1139-1145.

8. Rees CM, Pierro A, Eaton S (2007) Neurodevelopmental outcomes of neonates with medically and surgically treated necrotizing enterocolitis. Arch Dis Child Fetal Neonatal Ed 92(3): 193-198.

9. Ta BD, Roze E, van Braeckel KN, Bos AF, Rassouli-Kirchmeier R, et al. (2011) Long-term Neurodevelopmental Impairment in Neonates Surgically Treated for Necrotizing Enterocolitis: Enterostomy Associated with a Worse Outcome. Eur J Pediatr Surg 21(1): 58- 64.

10. Marion CW Henry, R Lawrence Moss (2005) Surgical therapy for necrotizing enterocolitis: bringing evidence to bedside. Seminars in Pediatric Surgery 14(3): 181-190.

11. Griffiths DM, Forbes DA, Pemberton PJ, Penn IA (1989) Primary anastomosis for necrotizing enterocolitis: a 12-year experience. J Pediatr Surg 24(6): 515-518.

12. Hofman FN, Bax NM, Van der Zee DC, WLM Kramer (2004) Surgery for necrotising enterocolitis: primary anastomosis or enterostomy? Pediatric Surgery International 20(7): 481-483. 
13. Kerl G Sylvester, Gigi Y Liu, Craig T, Albaneses, Arnold G Coran, N Scott Adzick, Thomas M. Krummel, Jean-Martin Laberge, Robert C Shamberger, Anthony A Caldamone (Eds.), Pediatric Surgery. ( $7^{\text {th }}$ edn.), Elsevier Saunders, USA, pp. 1187-1207.

14. Merritt TA, Pillers D, Prows SL (2003) Early NICU discharge of very low birth weight infants: a critical review and analysis. Semin Neonatol 8(2): 95-115.

15. Froehlich TE, Lanphear BP, Epstein JN, Barbaresi WJ, Katusic SK, et al (2007) Prevalence, recognition, and treatment of attention-deficit/ hyperactivity in national sample of US children. Arch Pediatr Adolesc Med 161(9): 857-864.
16. Visser SN, Danielson ML, Bitsko RH, Holbrook JR, Kogan MD, et al. (2014) Trends in the parent-report of health care provider-diagnosed and medicated attention-deficit/hyperactivity disorder: United States, 2003-2011. J Am Acad Child Adolesc Psychiatry 53(1): 34-46.

17. Altarac M, Saroha E (2007) Lifetime prevalence of learning disability among US children. Pediatrics 119(1): 77-83.

18. Allotey J, Zamora J, Cheong-See F, Kalidindi M, Arroyo-Manzano D, et al. (2018) Cognitive, motor, behavioural and academic performances of children born preterm: a meta-analysis and systematic review involving 64061 children. BJOG 125(1): 16-25.
This work is licensed under Creative Commons Attribution 4.0 Licens DOI: 10.19080/AJPN.2020.09.555821
Your next submission with Juniper Publishers will reach you the below assets

- Quality Editorial service

- Swift Peer Review

- Reprints availability

- E-prints Service

- Manuscript Podcast for convenient understanding

- Global attainment for your research

- Manuscript accessibility in different formats

( Pdf, E-pub, Full Text, Audio)

- Unceasing customer service

Track the below URL for one-step submission https://juniperpublishers.com/online-submission.php 